\title{
Long-Term Outcome and Quality of Life in Aortic Type A Dissection Survivors
}

\author{
Matthias Endlich ${ }^{1}$ Marwan Hamiko ${ }^{1}$ Christopher Gestrich ${ }^{1}$ Chris Probst ${ }^{1}$ Fritz Mellert ${ }^{1}$ \\ Kai Winkler ${ }^{1}$ Armin Welz ${ }^{1}$ Wolfgang Schiller ${ }^{1}$ \\ ${ }^{1}$ Department of Cardiovascular Surgery, University Hospital Bonn, \\ Bonn, Germany \\ Thorac Cardiovasc Surg 2016;64:91-99. \\ Address for correspondence Dr. med. Matthias Endlich, Department \\ of Cardiovascular Surgery, University Hospital Bonn, Sigmund-Freud- \\ Strasse 25, 53127 Bonn, Germany \\ (e-mail: matthias.endlich@ukb.uni-bonn.de).
}

\begin{abstract}
Keywords

- aortic dissection

- SF-36

- quality of life

- long-term outcome
\end{abstract}

\section{Introduction}

Acute aortic dissection type A (AADA) is a severe and complex disease that is often linked to diverse, possible complications. Without appropriate surgical treatment approximately $75 \%$ of all patients die within 14 days after the onset of symptoms. ${ }^{1}$ Because of advances in surgery, anesthesia and medical therapy postoperative outcome is steadily improving. ${ }^{2-4}$ Most published literature concerns about surgical outcome, survival of patients, and complications leading to disability. Postoperative QoL comparing physical and psychological status is rarely considered in this view. The following article concerns about long-term outcome and quality of life (QoL) after AADA, and focuses on the changes of QoL concerning physical and mental status.

\section{Methods}

\section{Patient Selection}

From January 1, 1999, until December 31, 2006, 120 patients received an emergency operation for Stanford type A aortic dissection. All patients were recorded and were asked to answer an SF-36 questionnaire during routine follow-up (FU). Four patients refused FU and seven were lost to FU resulting in 109 patients for this study group.

\section{Data Collection}

Dataset was acquired using SF-36 QoL questionnaire. The first SF-36 questionnaire $\left(\mathrm{FU}_{\mathrm{I}}\right)$ was obtained within $45 \pm 32$ months after surgery, the second $\left(\mathrm{FU}_{\mathrm{II}}\right), 46 \pm 10$ months thereafter. Some of the patients could not show up for their

(c) 2016 Georg Thieme Verlag KG Stuttgart · New York
DOI http://dx.doi.org/ 10.1055/s-0035-1548734. ISSN 0171-6425. 
92 Long-Term Outcome and QoL in AADA Survivors Endlich et al.

FU due to aging or movement to another state or country. In these cases the SF-36 FU was gathered by telephone call or mail.

\section{SF-36 Questionnaire}

SF-36 questionnaire is used as a measuring tool for healthrelated QoL. It is a multipurpose, short-form health survey with 36 questions and also a generic measure, as opposed to one that targets a specific age, disease, or treatment group. It yields an eight subscore profile of functional health and wellbeing scores, psychometrically based physical and mental health summary measures and a preference-based health utility index. The first version was developed in 1994 by the RAND Corporation. The German version of SF-36 questionnaire was translated by Bullinger in $1995 .^{5}$ - Fig. 1 shows an overview of the SF-36 and its subscores.

The three subscores include Physical Functioning (PF), Role-Physical (RP), and Bodily-Pain (BP) that correlate highest with the physical component and have the most influence on the Physical Component Summary (PCS) measure. ${ }^{6}$ The mental component correlates most highly with the subscores of Mental Health (MH) and Role-Emotional (RE), which also contribute most to the scoring of the MCS measure. The three subscores general health (GH), vitality (VT), and social functioning (SF) have noteworthy correlations with both components. The SF-36 measurement model was validated in several European countries in $1998 .^{7}$ The German version of the SF-36 was used in the Bundes-Gesundheits survey of 1998 and normed on basis of 6,964 persons. $^{8}$ In our observation, we used the German version of the SF-36 questionnaire.

\section{Statistical Analysis}

The statistical analysis was performed with SPSS for Windows, Version 19.0 (SPSS Inc., Chicago, Illinois). Statistics are summarized as mean value and median for continuous variables. Mean values are given with standard deviation (SD)
Items

3a. Vigorous Activities
3b. Moderate Activities
3c. Lift, Carry Groceries
3d. Climbs Several Flights
3e. Climb One Flight
3f. Bend, Kneel
3g. Walk Mild
3h. Walk Several Blocks
3i. Walk One Block
3j. Bathe, Dress
4a. Cut Down Time
4b. Accomplished Less
4c. Limited In Kind
4d. Had Difficulty
7. Pain-Magnitude
8. Pain-Interfere
1. EVGFP Rating
11a. Sick Easier
11b. As Healthy
11c. Health To Get Worse
11d. Health Excellent
9a. Pep/Life
9e. Energy
9g. Worn Out
9i. Tired
6. Social-Extent
10. Social-Time
5a. Cut Down Time
5b. Accomplished Less
5c. Not Careful
9b. Nervous
9c. Down In Dumps
9d. Peacefull
9f. Blue / Sad
9h. Happy

Summary Score Subscores

Summary Scores

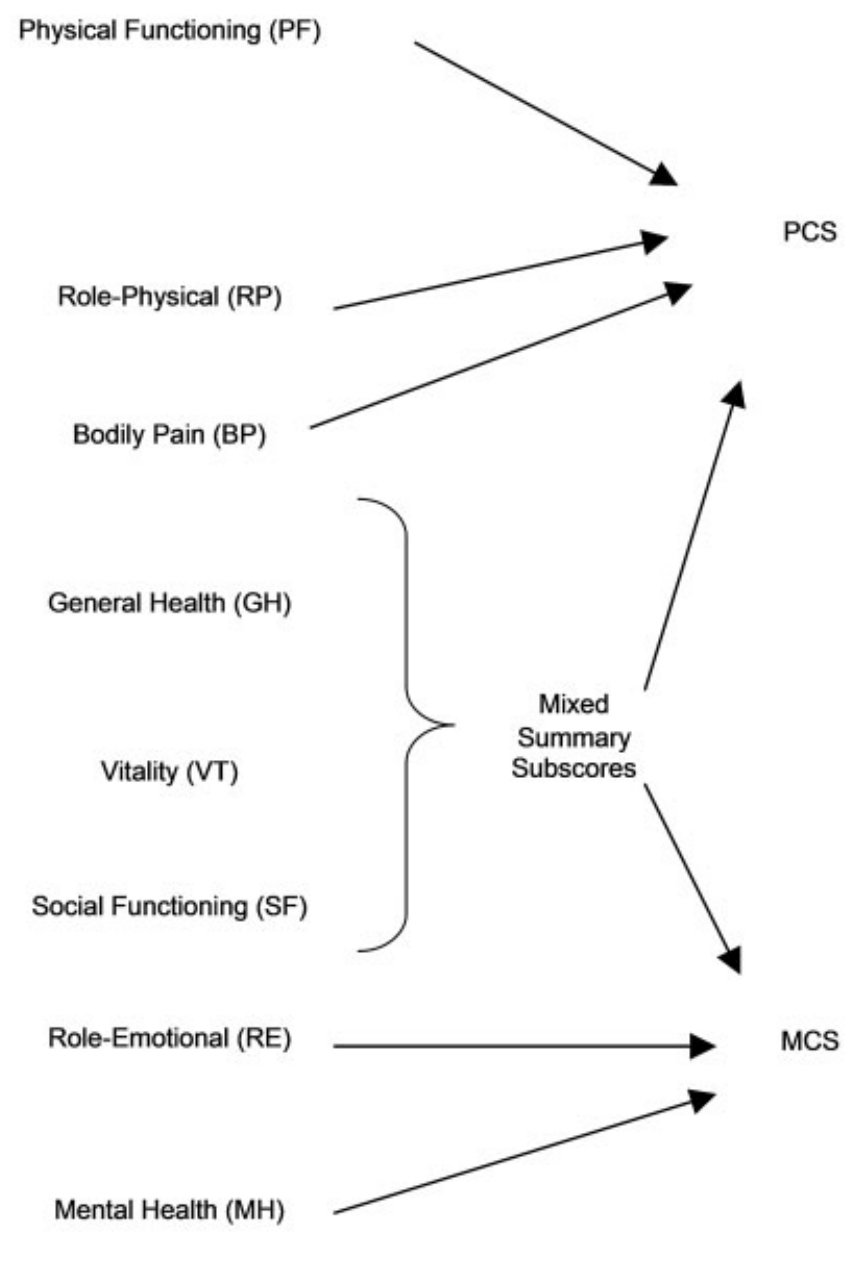

Fig. 1 SF-36 measurement model from Ware, Kosinski, and Keller (SF-36 Health Survey Update 1994). MCS, Mental Component Summary; PCS, Physical Component Summary. 
in the form mean \pm SD. Measures of dispersion are summarized as standard deviation or quartiles. The collection of physical health (PCS), mental health (MCS), and the subscores for the SF-36 questionnaire was done by using a standardized evaluation macro for SPSS by Testzentrale GmbH (Hochgrefe Verlag, Göttingen, Germany). The standard distribution of continuous variables was checked by Kolmogorov-Smirnov test. Most tested variables showed no standard distribution. Differences between two linked, nonstandard distributed samples were checked by Wilcoxon test. The comparison between patient sample and normal population or samples of other diseases was performed by using the $t$-test. Influence of single factors on the research groups was checked by Kruskal-Wallis test. For all tests bilateral significance was tested and accepted as significant with $p<0.05$. Survival was analyzed by using Kaplan-Meyer test. Log-Rank test was used for analyzing mortality rate. Arithmetic charts were drawn with SPSS and Microsoft Excel.

\section{Results}

\section{Demographics}

Of the 120 patients with AADA 84 (70.0\%) were males and 36 (30.0\%) females, with a mean age of $59.8 \pm 12$ years. There were two $(1.7 \%)$ patients with Marfan syndrome. Of the patients, 115 (95.8\%) had arterial hypertension, 69 (57.5\%) were smokers, 56 (46.7\%) showed hyperlipidemia, and 34 (28.3\%) had a body mass index $>30$. Furthermore, there were 16 (13.3\%) patients with insulin-dependent diabetes mellitus type 2 and seven (5.8\%) with previous myocardial infarction.

\section{Clinical Presentation}

Preoperatively, 67 (55.8\%) patients had congestive heart failure classified by New York Heart Association (NYHA) as class III or IV, 54 (45\%) showed electrocardiographic (ECG) changes and $50(41.7 \%)$ pericardial effusion, 37 (30.8\%) had a syncope, and 33 (27.5\%) patients had by neurologic complications or peripheral malperfusion. Moreover, 24 (20\%) of all patients developed signs of unstable circulation though maximum catecholamine therapy; 11 (9.2\%) patients were in need for cardiopulmonary resuscitation (CPR) on admission.

\section{Operative Techniques}

Operative procedures consisted of supracoronary replacement of the ascending aorta in 103 (85.8\%) patients, supracoronary replacement of the ascending aorta combined with subcoronary aortic valve replacement in nine (7.5\%) cases. The replacement of the ascending aorta and aortic valve with a valved conduit (Bentall-DeBono procedure) was performed in five (4.2\%) cases, and replacement of the ascending aorta with reimplantation of the coronary arteries and the aortic valve (David procedure) in two (1.7\%) cases. A Cabrol procedure (replacement of the ascending aorta and the aortic valve with a valved conduit and reimplantation of the coronary arteries into an additional conduit) was done in one (0.8\%) case. Of the patients, 13 (10.8\%) had previous cardiac surgery. Additionally, coronary artery bypass grafting (CABG) was performed in five $(4.2 \%)$ patients and mitral valve replace- ment in one (0.8\%) patient. In 115 (95.8\%) cases we performed the distal aortic anastomosis by open view, in deep hypothermia and circulatory arrest including partial aortic arch replacement of various expanses. In five (4.2\%) cases a CTevaluated, restricted dissection of the proximal ascending aorta was treated with supracoronary replacement of the ascending aorta.

The mean operative time was $382 \pm 121$ minutes; the mean circulatory arrest time was $38 \pm 23$ minutes (median $=35$ minutes). Selective brain perfusion was performed in 31 (25.8\%) cases (our department started to use selective brain perfusion on a regular basis for AADA patients in 2004). The femoral artery was cannulized in 91 (75.8\%), subclavian artery in 23 (19.2\%), the ascending aorta in five (4.2\%) cases, and mixed cannulation of femoral and subclavian artery was performed in one $(0.8 \%)$ case.

\section{Postoperative Complications}

During the first 30 postoperative days there was a variety of complications. Of the patients, 54 (45\%) developed pleural effusion with need of pleural drainage and 46 (38.3\%) suffered from postoperative delirium. Rethoracotomy due to bleeding was performed in 33 (27.5\%) cases, 21 (17.5\%) needed hemodialysis, and $14(11.7 \%)$ patients suffered from permanent neurologic problems. Also, seven (5.8\%) patients developed septic symptoms during the first 30 days postoperatively. The mean period of ventilation was $28.3 \pm 8.1$ hours. The mean stay on the intensive care unit (ICU) was $15 \pm 17$ days.

Of the patients, 19 (15.8\%) died during the first 30 postoperative days, eight (7.7\%) due to therapy-resistant low cardiac output, and four (3.3\%) due to multiorgan failure (MOF) with sepsis. Two (1.7\%) patients died during operation, another two (1.7\%) due to early postoperative rupture, yet another two (1.7\%) due to disseminated intravascular coagulation, and one $(0.8 \%)$ patient died due to severe neurologic malperfusion, resulting in hypoxic brain damage.

During the long-term FU of $99.2 \pm 6$ months another 22 (18.3\%) patients died. In 10 (9.2\%) cases the cause of death is unknown. Of the patients, four (3.3\%) died due to aortoesophageal fistula, three (2.5\%) due to a serious stroke. Moreover, two $(1.7 \%)$ patients died due to cancer, two $(1.7 \%)$ due to pneumonia, and one $(0.8 \%)$ suffered from redissection with aortic rupture.

Of the 109 observed patients, 17 (15.6\%) underwent operative redo during observation and six (5.5\%) had to be operated for hemodynamic relevant aortic valve regurgitation. Thoracic endovascular aortic replacement (TEVAR) was performed in five (4.6\%) cases due to aneurysmatic enlargement of the descending aorta. A complex reoperation with stenting of the descending aorta, total aortic arch replacement, and abdominal aortic stenting was performed in two (1.8\%) cases. A suture aneurysm was reoperated in one $(0.9 \%)$ case.

\section{Survival}

During long-term survival survey four patients refused FU, seven were lost to FU. Of the 109 included patients, 41 died within the observational period. Of these 19 (17.4\%) died 
during the first 30 postoperative days and another six (5.5\%) died during the first postoperative year. Within the observed 12 years the survival rate after AADA was $62.4 \%$ (-Fig. 2).

The results show that most of the patients die within the first postoperative year. For long-term analysis we compared the patient group surviving the first postoperative year $(n=84)$ with a group of German normal population, matched for sex, age, and the year of AADA occurrence. The calculated survival of the normal population sample group was $83.3 \%$ for a period of 12 years. The survivors of the first postoperative year after AADA showed a long-term survival of 82.1\% after a 12-year observational period. In long-term survey no patient died after the eighth postoperative year.

Further, we compared the influence of the single factors age, sex, selective brain perfusion, and operative techniques on survival. The Cox-regression showed that none of these factors directly influenced the survival of patients. Furthermore, we analyzed, whether neurologic complications are influenced by selective brain perfusion or not. In this study Cox-regression again showed no influence of selective brain perfusion in the event of neurologic complications, but the number of patients treated with selective brain perfusion included in this study is rather low, as explained previously. Moreover, we analyzed whether the cannulation technique or circulatory arrest time is an influencing factor for survival or neurologic complications. The Cox-regression again showed no significant difference between antegrade and retrograde perfusion.

\section{Quality of Life after AADA}

SF-36 questionnaire was obtained $45 \pm 32$ months $\left(\mathrm{FU}_{\mathrm{I}}\right)$ after primary surgery and then $46 \pm 10$ months later $\left(\mathrm{FU}_{\mathrm{II}}\right)$. In the first FU 77 patients were included. In the second FU only patients from the first FU were screened. Seven patients died in the meantime and eight patients were lost to FU. For first step, general comparison of $\mathrm{FU}_{\mathrm{I}}$ and $\mathrm{FU}_{\mathrm{II}}$, only patients answering both FUs properly $(n=59)$ were included. During analysis of the SF-36 questionnaire two superior scores were built: the PCS and the MCS.

First, we compared the two FU results. PCS in the first FU, $\mathrm{PCS}_{\mathrm{I}}$ was $43.2 \pm 11.0$ points and $\mathrm{MCS}\left(\mathrm{MCS}_{\mathrm{I}}\right)$ was $48.1 \pm 11.9$. In the second FU PCS was $38.4 \pm 9.9\left(\right.$ PCS $\left._{\text {II }}\right)$ and MCS

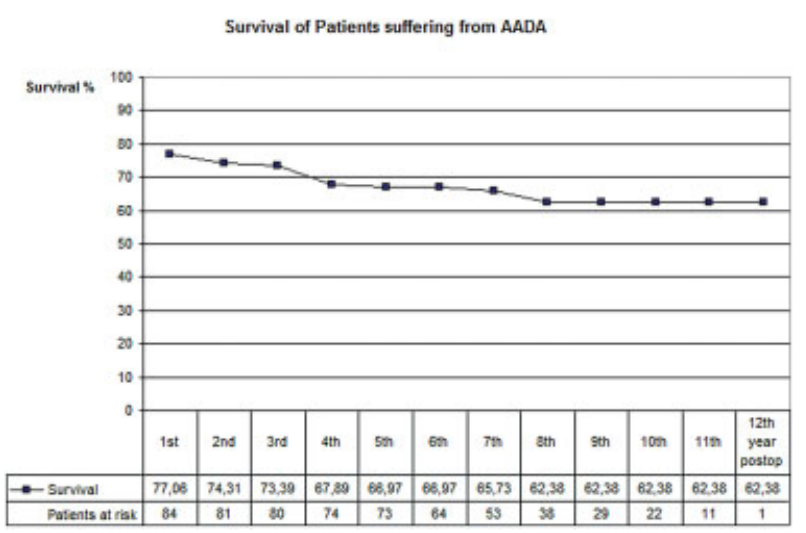

Fig. 2 Kaplan-Meyer long-term survival curve for patients with AADA.
$33.3 \pm 11.9\left(\mathrm{MCS}_{\mathrm{II}}\right)$, which is a significant decrease with $\mathrm{p}_{\mathrm{PCS}}=0.013$ and $\mathrm{p}_{\mathrm{MCS}}<0.001$.

The comparison with German normal population value of 1998 shows that PCS of $\mathrm{FU}_{\mathrm{I}}$ is significantly worse with $p=0.001$. The $\mathrm{MCS}_{\mathrm{I}}$ shows a negative trend in comparison with the normal population with $p=0.056$. The comparison of PCS $_{\text {II }}$ again was significantly worse than the norm values with $p<0.001$. $\mathrm{MCS}_{\text {II }}$ now is also significantly worse compared with the normal population with $p<0.001$ (-Fig. 3 ).

Next, we compared PCS and MCS of both FUs with different diseases of the 1998 Bundes-Gesundheits survey. Diseases included were myocardial infarction (MI), patients with coronary heart disease without infarction (CHD), and cancer.

$\mathrm{PCS}_{\mathrm{I}}$ is significantly better than PCS of myocardial infarction group or coronary heart disease without infarction group with $\mathrm{p}_{\mathrm{MI}}=0.005$ and $\mathrm{p}_{\mathrm{CHD}}=0.002$, respectively. In the cancer group there is no statistic difference. In $\mathrm{FU}_{\mathrm{I}}$ the observed patients showed a significantly worse MCS compared with the MI group with $p=0.015$. A negative trend is seen in relation to the coronary heart disease group with $p=0.053$.

$\mathrm{PCS}_{\mathrm{II}}$ showed no statistic difference in comparison to all other groups. The comparison of $\mathrm{MCS}_{\text {II }}$ showed a significantly worse result in all test groups with $p<0.001$ in all tests

(-Fig. 4).

Next, we checked the influence of single factors on PCS and MCS. We defined the following factors: pre- and postoperative complications, neurologic complications, or preoperative $\mathrm{CPR}$, postoperative neurologic complications, idle period on the ICU, length of ICU stay, and cannulation technique. Influence of single factors on the PCS and MCS was checked by $U$-test. Neither in $\mathrm{FU}_{\mathrm{I}}$ nor in $\mathrm{FU}_{\mathrm{II}}$ was any significance found.

Further on, we checked whether the time span between operation and the first FU could be an influencing factor for QoL. Therefore, we divided the patients according to the postoperative year the first FU took place. We created seven subgroups: in subgroup 1 the first FU took place until the end of the second postoperative year, in subgroup 2 the first FU took place until the end of the third postoperative year, and so on, until subgroup 7 in which the first FU was obtained until the end of the eighth postoperative year. Kruskal-Wallis test



Fig. 3 SF-36 Component Summary Scores of patients surviving AADA in $\mathrm{FU}_{\mathrm{I}}, \mathrm{FU}_{\mathrm{II}}$, and normal population; $p$ values according to KruskalWallis test. 


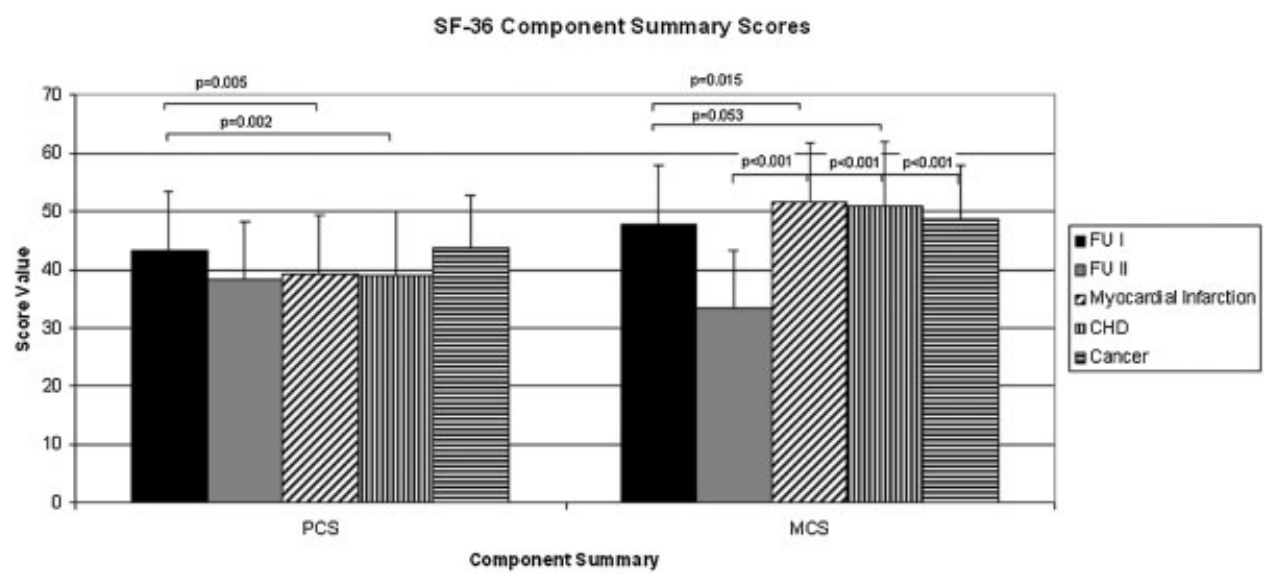

Fig. 4 SF-36 Component Summary Scores in patients surviving AADA in $\mathrm{FU}_{\mathrm{I}}, \mathrm{FU}_{\mathrm{II}}$, myocardial infarction, coronary heart disease, and cancer; $\mathrm{p}$ values according to Kruskal-Wallis test.

shows no relation of time span $\left(\mathrm{FU}_{\mathrm{I}}\right)$ and $\mathrm{QoL}\left(\mathrm{FU}_{\mathrm{I}}\right)$. The same is true for $\mathrm{QoL}\left(\mathrm{FU}_{\mathrm{II}}\right)$.

Finally, we checked if patient's age at the AADA event is an influencing factor for long-term QoL. Therefore, we subdivided our patients for age in five different age-groups: age group 1: 31 to 40 years, age group 2: 41 to 50 years, age group 3: 51 to 60 years, age group 4: 61 to 70 years, and age group 5: $>70$ years.

In $\mathrm{FU}_{\mathrm{I}}$, we found none of the component summary scores $\left(\mathrm{PCS}_{\mathrm{I}}\right.$ and $\mathrm{MCS}_{\mathrm{I}}$ ) showed any statistic difference in relation to age group. The same is true regarding subscores influencing only PCS and subscores having noteworthy influence on both PCS and MCS. Mental health (MH) subscore influencing only MCS shows the younger the patients, the lower the score with $p=0.008$ according to Kruskal-Wallis test ( - Figs. 4 and 5, - Table 1).

For $\mathrm{FU}_{\mathrm{II}}$, we found again no significance for PCS and the related subscores. Analysis of MCS $_{\text {II }}$ showed a significant relation between patient's age and QoL with $p=0.032$ according to Kruskal-Wallis test. Again, the younger the patients, the lower the MCS is. Within the group of subscores having noteworthy influence on both PCS and MCS (general health, vitality, and social functioning), the vitality and social functioning scores show a statistical trend with $p=0.058$ and $p=0.072$, respectively. Of the subscores role emotional and mental health influencing only MCS just mental health shows a trend with $p=0.07$. Again, the younger the patients, the lower the score is (-Figs. $\mathbf{5}$ and $\mathbf{6}, \mathbf{-}$-Table $\mathbf{1}$ ).

Next, we compared the age groups of $\mathrm{FU}_{\mathrm{I}}$ and $\mathrm{FU}_{\mathrm{II}}$ by means of Mann-Whitney $U$-test. The results show that there is a significant decrease in MCS and linked subscores in $\mathrm{FU}_{\mathrm{II}}$ in almost all compared groups. In the three subscores only linked to PCS, there is a difference in between $\mathrm{FU}_{\mathrm{I}}$ and $\mathrm{FU}_{\mathrm{II}}$ just for the subscore Role-Physical in higher-aged groups (patients aged $>50$ years). PCS is significantly worse in $\mathrm{FU}_{\mathrm{II}}$ only in age group 5 (patients aged $>70$ years) ( - Table 2 ).

Finally, we compared the SF-36 component summary scores (PCS, MCS) in $\mathrm{FU}_{\mathrm{I}}$ and $\mathrm{FU}_{\mathrm{II}}$ according to age groups

\section{SF-36 Sub-Score Mental Health FU I, FU II and Normal Population}

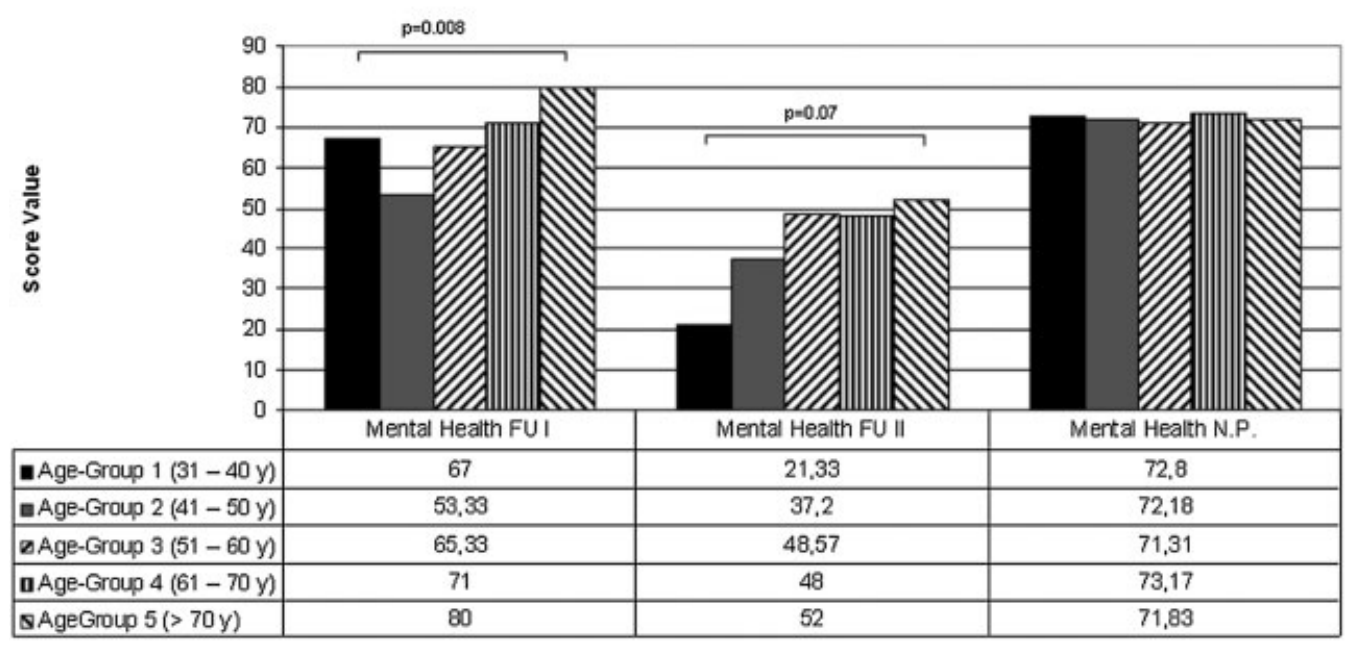

Fig. 5 SF-36 subscore of Mental Health in $\mathrm{FU}_{1}, \mathrm{FU}_{\|}$, and normal population, p-values according to Kruskal-Wallis test. 
SF 36 MCS FU I, FU II and Normal Population

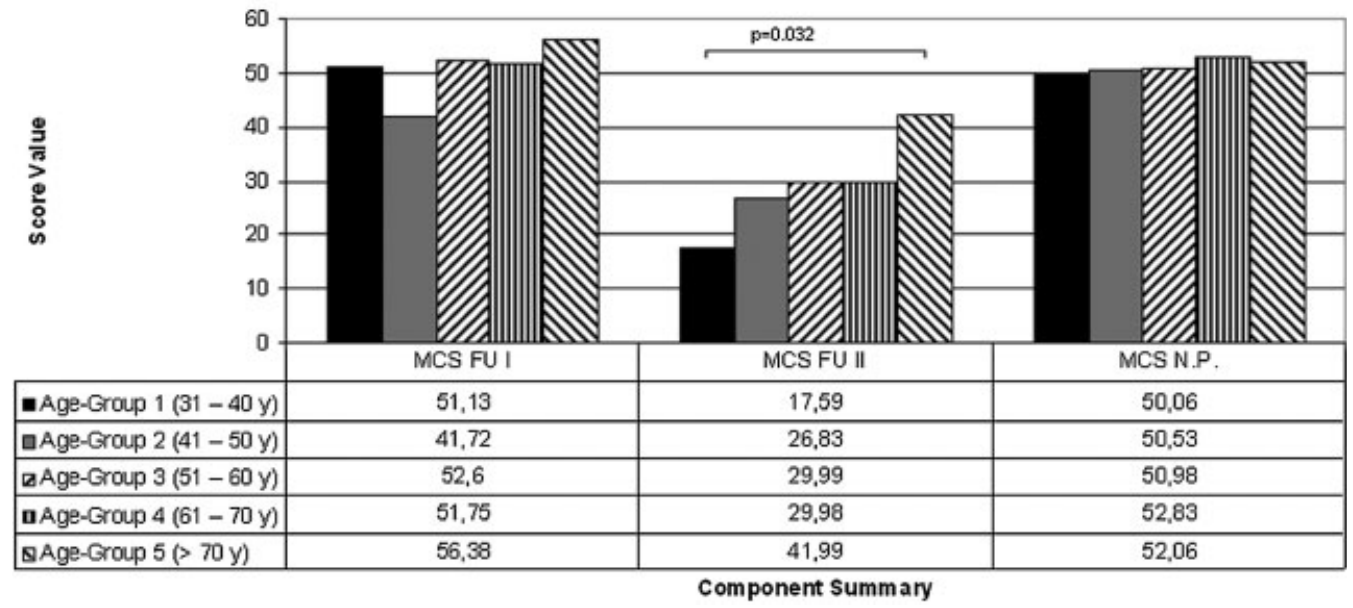

Fig. 6 SF-36 Mental Component Summary (MCS) score in FU, FU II, and normal population (N.P.); $p$ values according to Kruskal-Wallis test.

with the appropriate groups of German normal population. In $\mathrm{FU}_{\mathrm{I}}$ there is no significant difference for PCS and MCS except for age group 2 (41-50 years), whereas in FU II PCS and MCS showed a significant decrease in all examined age groups compared with the German normal population (-Table 2).

\section{Discussion}

Our 30 days results show almost the same rate and sort of complications like other large studies. ${ }^{9}$ The number and percentage of 30 days postoperative complications is still high, but the improvement in perioperative

Table 1 Comparison of SF-36 data of $\mathrm{FU}_{\text {I }}$ and $\mathrm{FU}_{\text {|I }}$ stratified by age groups

\begin{tabular}{|c|c|c|c|c|c|}
\hline SF-36 score & $\begin{array}{l}\text { Age group } 1 \\
(31-40 y) \\
n\left(F U_{1}\right)=4 \\
n\left(F U_{I I}\right)=3\end{array}$ & $\begin{array}{l}\text { Age group } 2 \\
(41-50 \mathrm{y}) \\
n\left(\mathrm{FU}_{\mathrm{l}}\right)=12 \\
n\left(\mathrm{FU}_{\mathrm{II}}\right)=10\end{array}$ & $\begin{array}{l}\text { Age group } 3 \\
(51-60 \text { y) } \\
n\left(F_{l}\right)=24 \\
n\left(F_{l I}\right)=21\end{array}$ & $\begin{array}{l}\text { Age group } 4 \\
(61-70 y) \\
n\left(F_{\mathrm{l}}\right)=17 \\
n\left(\mathrm{FU}_{\mathrm{II}}\right)=13\end{array}$ & $\begin{array}{l}\text { Age group } 5 \\
(>70 y) \\
n\left(F_{1}\right)=20 \\
n\left(F_{\| I}\right)=15\end{array}$ \\
\hline \multicolumn{6}{|l|}{ PCS subscores } \\
\hline Physical functioning & 0.154 & 0.552 & 0.147 & 0.95 & 0.105 \\
\hline Role-Physical & 0.127 & 0.452 & 0.021 & 0.097 & 0.007 \\
\hline Bodily Pain & 0.463 & 0.921 & 0.853 & 0.747 & 0.108 \\
\hline PCS & 0.289 & 0.744 & 0.241 & 0.593 & 0.035 \\
\hline \multicolumn{6}{|l|}{ Mixed subscores } \\
\hline General health & 0.034 & 0.012 & 0.001 & 0.001 & $<0.001$ \\
\hline Vitality & 0.032 & 0.014 & 0.002 & 0.001 & $<0.001$ \\
\hline Social functioning & 0.026 & 0.225 & 0.004 & 0.086 & 0.004 \\
\hline MCS & 0.034 & 0.041 & 0.005 & 0.001 & 0.003 \\
\hline \multicolumn{6}{|l|}{ MCS subscores } \\
\hline Role-Emotional & 0.066 & 0.025 & 0.02 & 0.002 & 0.25 \\
\hline Mental health & 0.032 & 0.063 & 0.018 & 0.002 & $<0.001$ \\
\hline
\end{tabular}

Abbreviations: FU, follow-up I; FU II, follow-up II; MCS, Mental Component Summary score; PCS, Physical Component Summary score.

Notes: Indicated are $p$ values according to Kruskal-Wallis test of FU $\mathrm{FU}_{1}$ against $\mathrm{FU}_{\|} .$. Both MCS and PCS are composed by their subscores and the mixed subscores according to - Fig. 1. $p$ Values with a level of significance less than 0.05 are marked in bold numbers and between 0.05 and 0.1 are marked in italics. 
Table 2 Comparison of SF-36 component summary scores of FU, and FU II with normal population

\begin{tabular}{|c|c|c|c|c|c|c|c|}
\hline Age group (y) & FU & Tested score & Mean (group) & Mean (normal population) & $n$ & $p$ & Mean difference \\
\hline & & \multicolumn{6}{|l|}{ PCS } \\
\hline 1. $(31-40)$ & 1 & & 50.4 & 51.4 & 4 & 0.758 & -1.1 \\
\hline 2. $(41-50)$ & 1 & & 39.3 & 49.2 & 12 & 0.027 & -9.9 \\
\hline 3. $(51-60)$ & 1 & & 43.7 & 45.6 & 24 & 0.475 & -1.9 \\
\hline 4. $(61-70)$ & I & & 41.9 & 43.9 & 17 & 0.495 & -2.1 \\
\hline 5. $(>70)$ & 1 & & 44.1 & 41.8 & 20 & 0.367 & 2.4 \\
\hline & & \multicolumn{6}{|l|}{ MCS } \\
\hline 1. $(31-40)$ & 1 & & 45.9 & 50.1 & 4 & 0.517 & -4.1 \\
\hline 2. $(41-50)$ & 1 & & 41.2 & 50.5 & 12 & 0.067 & -9.3 \\
\hline 3. $(51-60)$ & $\mathrm{I}$ & & 47.2 & 51 & 24 & 0.172 & -3.7 \\
\hline 4. $(61-70)$ & 1 & & 49.2 & 52.8 & 17 & 0.251 & -3.6 \\
\hline 5. $(>70)$ & 1 & & 52.2 & 52.1 & 20 & 0.997 & 0.1 \\
\hline & & \multicolumn{6}{|l|}{ PCS } \\
\hline 1. $(31-40)$ & II & & 36.1 & 51.4 & 3 & 0.246 & -15.3 \\
\hline 2. $(41-50)$ & II & & 37.9 & 49.2 & 10 & 0.009 & -11.2 \\
\hline 3. $(51-60)$ & II & & 40 & 45.6 & 21 & 0.012 & -5.6 \\
\hline 4. $(61-70)$ & 11 & & 39.1 & 43.9 & 13 & 0.162 & -4.8 \\
\hline 5. $(>70)$ & II & & 36 & 41.8 & 15 & 0.015 & -5.7 \\
\hline & & \multicolumn{6}{|l|}{ MCS } \\
\hline 1. $(31-40)$ & II & & 17.7 & 50.1 & 3 & 0.004 & -32.3 \\
\hline 2. $(41-50)$ & II & & 29.4 & 50.5 & 10 & $<0.001$ & -21.1 \\
\hline 3. $(51-60)$ & 11 & & 34.6 & 51 & 21 & $<0.001$ & -16.3 \\
\hline 4. (61-70 years) & 11 & & 31.6 & 52.8 & 13 & $<0.001$ & -21.3 \\
\hline 5. $(>70)$ & II & & 38.9 & 52.1 & 15 & 0.001 & -13.1 \\
\hline
\end{tabular}

Abbreviations: FU, follow-up I; FU II, follow-up II (46 \pm 10 mo after FU ); MCS, Mental Component Summary score; PCS, Physical Component Summary score.

Notes: $p$ Values indication level of significance related to the comparison of normal population. $p$ Values with a level of significance less than 0.05 are marked in bold numbers and between 0.05 and 0.1 are marked in italics.

management and postoperative care constantly raises survival.

Today, there is a common sense that antegrade perfusion; via cannulation of Arteria subclavia dextra, with selective cerebral perfusion should be applied for surgery on aortic dissection type A. Multiple studies show a benefit concerning survival and neurologic complications with the antegrade approach. ${ }^{10-13}$ Others, like the analysis of GERAADAdataset (years 2006 until 2010), with 2,137 patients, showed no significant difference between the antegrade and the retrograde perfusion technique. ${ }^{14}$ Supposing that there is an influence of perfusion technique to neurologic complications and survival, an influence on postoperative QoL could be assumed as well. In our study we could not find any difference between the two cannulation techniques concerning survival, neurologic complications, or QoL. This seems not surprising as the number of patients with antegrade perfusion is quite low in this historical group of patients.
This study mainly focuses on long-term outcome and QoL after AADA surgery. The Kaplan-Meyer survey shows a lethality of $37.6 \%$ after 12 years in the AADA group. Compared with the calculated lethality of $16.4 \%$ in normal population during the same period, this is quite high. Furthermore, the Kaplan-Meyer survey shows that most patients suffering from AADA die within the first postoperative year, most of them within the first 30 days after surgery due to complications like low cardiac output, MOF, or bleeding.

QoL after thoracic aortic surgery was a point of interest in various papers. In 1999 Olsson et al used the SF-36 for measuring QoL in patients undergoing thoracic aortic surgery for all kind of disease. They rated QoL as acceptable, but a decrease in PCS, MCS, and subscores was recognized, worst in subscores of Role-Emotional, and Role-Physical. ${ }^{15}$ In 2007 Stalder et al published their data for QoL after aortic root surgery. They showed that surgical treatment of the aortic root has no decreasing effect on QoL compared with normal population using SF-36 questionnaire. ${ }^{16} 2009$ Lohse et al used 
SF-36 for measuring QoL after replacement of the ascending aorta in patients with true aneurysms. They concluded that this invasive procedure can be performed with good midterm results and acceptable QoL without further differentiation. ${ }^{17}$ Campbell-Lloyd et al assessed long-term QoL in patients after suffering from AADA using EQ-5D (Euroqol questionnaire) in 2010. Forty-eight percent of patients recorded full health with an overall mean index of 0.854 (where the best possible score is 1) using the US preference weighted index score. ${ }^{18}$ In 2012 Kobuch et al published data for QoL after surgery of ascending aorta and aortic arch with selective antegrade cerebral perfusion. Sickness-impact-profile (SIP) that was used for rating QoL showed excellent results after aortic surgery. ${ }^{19}$

Comparison of the presented study to these publications is limited. The patients included in the study of Olsson et al were not only patients with emergent repair of AADA but also patients with aortic aneurysm. Moreover, only $41 \%$ of all operated cases had deep hypothermia with circulatory arrest. In our study 115 (95.8\%) operations were performed using deep hypothermia and circulatory arrest. A large number of patients were included by Stalder et al, but again most of the patients undergone an elective aortic root repair based on a various number of diseases and only a small number of patients were treated with emergent aortic repair due to AADA. Furthermore, Lohse et al included only patients getting a nonemergent aortic repair and excluded all patients with emergent aortic repair due to AADA, aortic rupture or intramural hematoma. Campbell et al performed full arch replacement in $14 \%$ of all cases and detected arch replacement as only predictor for poor neurological outcome. In our collective no full arch replacement was done. Kobuch at al analyzed a collective of patients where $100 \%$ of the operations were performed with antegrade cerebral perfusion. In our study the number of patients with antegrade cerebral perfusion is quite low. Naturally, analysis of different collectives of patients and furthermore, comparison of emergent and nonemergent surgical approaches, must lead to completely different results. Additionally, the more specific a disease, the more limited the comparability of SF-36 questionnaire with other evaluation tools for QoL, for example, EQ-5D is. ${ }^{20}$

From our knowledge, to date, there is no two-point postoperative FU study concerning QoL in AADA. In contrast to single-point FU evaluation, which gives a snapshot, twopoint measurements allow for an estimation concerning the course of this chronic disease. For evaluation of long-term outcome and QoL in AADA survivors, we used the SF-36 questionnaire, as it is a well-accepted and highly validated tool with a large evaluated dataset for the German population.

$\mathrm{FU}_{\mathrm{I}}$ shows that patients surviving AADA have a significantly worse PCS after $45 \pm 32$ months than the general population, which is not true for MCS. The second FU obtained $46 \pm 10$ months later showed a significant decrease in PCS and MCS. The decrease, during the observational period, is strongest in MCS and linked subscores. Regarding PCS, the decay during the FU period could be explained by the natural course of PCS, which is decreasing with age as shown in -Table 2. In contrast, MCS in general population is increasing with age that makes the decay in our study group even more pronounced (-Table $\mathbf{2}$ ). Age group-related analysis of subscores influencing PCS is giving few significant results. This could be explained by small patient numbers per group. Regarding the analysis according to age groups and QoL of matched normal population in $\mathrm{FU}_{\mathrm{I}}$, the PCS is in none, but one age group (41-50 years) worse than in the related age group of the normal population. However in $\mathrm{FU}_{\mathrm{II}}$ three age groups show significantly worse results although the number of patients included in $\mathrm{FU}_{\mathrm{II}}$ is smaller than in $\mathrm{FU}_{\mathrm{I}}$. This suggests a negative effect on the physical component of QoL in the long-term course of the disease. Regarding subscores linked to MCS, a significant decay of $\mathrm{QoL}$ between $\mathrm{FU}_{\mathrm{I}}$ and $\mathrm{FU}_{\mathrm{II}}$ is found in almost all age groups. Combined with the fact that MCS is increasing with age in normal population, this result gives strong evidence for a negative effect of the disease to the mental aspects of QoL.

Although we have seen no significant effects of postoperative complications or length of stay on ICU to $\mathrm{QoL}$ in $\mathrm{FU}_{\mathrm{I}}$ or $\mathrm{FU}_{\mathrm{II}}$, such effects cannot be excluded as sample sizes are rather small. Nevertheless, as most patients with severe complications did not survive until $\mathrm{FU}_{\mathrm{I}}$, we rate the impact of complications on our results as small concerning long-term survivors.

Santini et al recognized a generalized perception of independence and well-being comparable to an age-matched population in patients older than 75 years suffering from AADA using SF-36 test with a mean FU of $44 \pm 38$ months. $^{21}$ The corresponding age group ( $>70$ years) of our study showed similar results for $\mathrm{FU}_{\mathrm{I}}$ but not for $\mathrm{FU}_{\mathrm{II}}$. In $\mathrm{FU}_{\mathrm{II}} \mathrm{QoL}$ was significantly worse compared with normal population in PCS and MCS (-Table 2).

Remarkably, the decay of MCS is related to patient's age. The younger the patient, the worse was the decay of MCS (-Fig. 6). Reasons for our findings, which are supported by numerous doctor and patient discussions, seem to be multifactorial, with a high rate of complications on the long-term. The ongoing need for FU and medication, as well as the risk of complications, implies constant disease awareness and a feeling of imminent danger. The older patients are, the more they are used to handle sickness and limitations of their lifetime. For younger patients and their social environment, coping with this issue is uncommon and therefore more stressful. Younger patients often lose their job, or require occupational retraining, which is not the case for retired patients missing occupational stress per se. In our opinion, the combination of those factors lead to the decay of mental status, especially true in younger patients.

\section{Conclusion}

As expected, the QoL of long-term survivors after surgical treatment of AADA is impaired with regard to the normal population, as these patients are still suffering from this chronic disease. The impairment of mental components is more serious in relation to the physical components of QoL. Against our expectations, we showed that QoL did not improve in time, but got worse, which is especially true in younger patients. Psychological therapy has proven its use for 
improving QoL in a various number of other diseases. ${ }^{22,23}$ Therefore, we conclude that treatment and FU for AADA patients should include measures to improve mental processing of this chronic disease as, for example, psychological therapy.

Note

Parts of this article were presented at the annual meeting of the German Society for Thoracic and Cardiovascular Surgery. Date and venue of presentation: February 19, 2013, Messe Freiburg, 79108 Freiburg, Germany.

Conflict of interest

None declared.

\section{References}

1 Suzuki S, Masuda M. An update on surgery for acute type A aortic dissection: aortic root repair, endovascular stent graft, and genetic research. Surg Today 2009;39(4):281-289

2 Cook RC, Gao M, Macnab AJ, Fedoruk LM, Day N, Janusz MT. Aortic arch reconstruction: safety of moderate hypothermia and antegrade cerebral perfusion during systemic circulatory arrest. J Card Surg 2006;21(2):158-164

3 Suzuki S, Imoto K, Uchida K, Takanashi Y. Aortic root necrosis after surgical treatment using gelatin-resorcinol-formaldehyde (GRF) glue in patients with acute type A aortic dissection. Ann Thorac Cardiovasc Surg 2006;12(5):333-340

4 Weigang E, Nienaber CA, Rehders TC, Ince H, Vahl CF, Beyersdorf F. Management of patients with aortic dissection. Dtsch Arztebl Int 2008;105(38):639-645

5 Bullinger M. German translation and psychometric testing of the SF-36 Health Survey: preliminary results from the IQOLA Project. International Quality of Life Assessment. Soc Sci Med 1995;41(10): 1359-1366

6 Ware JE Jr, Sherbourne CD. The MOS 36-item short-form health survey (SF-36). I. Conceptual framework and item selection. Med Care 1992;30(6):473-483

7 Wagner A, Gandek B, Aaronson N, et al. Cross-cultural comparisons of the content of the SF-36 translations across 10 countries: results from the International Quality of Life Assessment Project. J Clin Epidemiol 1998;51(11):925-932

8 Ellert U, Der Bellach BM. Der SF-36 im Bundes-Gesundheitssurvey -Beschreibung einer aktuellen Normstichprobe. Gesundheitswesen 61. Sonderheft 1999;2:184-190

9 Conzelmann LO, Krüger T, Hoffmann I, et al; Teilnehmenden GERAADA-Zentren. German Registry for Acute Aortic Dissection
Type A (GERAADA): initial results [in German]. Herz 2011;36(6): 513-524

10 Kallenbach K, Beller CJ, Karck M. Strategien der arteriellen Kanülierung bei akuter Aortendissektion Typ A zum Anschluss der Herz-Lungen-Maschine. Zeitschrift für Herz-, Thorax- und Gefäßchirurgie 2012;26(1):7-13

11 Schurr UP, Emmert MY, Berdajs D, et al. Subclavian artery cannulation provides superior outcomes in patients with acute type-A dissection: long-term results of 290 consecutive patients. Swiss Med Wkly 2013;143:w13858

12 Tiwari KK, Murzi M, Bevilacqua S, Glauber M. Which cannulation (ascending aortic cannulation or peripheral arterial cannulation) is better for acute type A aortic dissection surgery? Interact Cardiovasc Thorac Surg 2010;10(5):797-802

13 Nouraei SM, Nouraei SA, Sadashiva AK, Pillay T. Subclavian cannulation improves outcome of surgery for type A aortic dissection. Asian Cardiovasc Thorac Ann 2007;15(2):118-122

14 Conzelmann LO, Hoffmann I, Blettner M, et al; GERAADA Investigators. Analysis of risk factors for neurological dysfunction in patients with acute aortic dissection type A: data from the German Registry for Acute Aortic Dissection type A (GERAADA). Eur J Cardiothorac Surg 2012;42(3):557-565

15 Olsson C, Thelin S. Quality of life in survivors of thoracic aortic surgery. Ann Thorac Surg 1999;67(5):1262-1267

16 Stalder M, Staffelbach S, Immer FF, et al. Aortic root replacement does not affect outcome and quality of life. Ann Thorac Surg 2007; 84(3):775-780, discussion 780-781

17 Lohse F, Lang N, Schiller W, et al. Quality of life after replacement of the ascending aorta in patients with true aneurysms. Tex Heart Inst J 2009;36(2):104-110

18 Campbell-Lloyd AJ, Mundy J, Pinto N, et al. Contemporary results following surgical repair of acute type A aortic dissection (AAAD): a single centre experience. Heart Lung Circ 2010;19(11):665-672

19 Kobuch R, Schelker E, Schmid C, Hirt S, Amann M, Diez C. Quality of life following surgery of ascending aorta and aortic arch with selective antegrade cerebral perfusion. Thorac Cardiovasc Surg 2012;60(8):496-500

20 Rowen D, Brazier J, Roberts J. Mapping SF-36 onto the EQ-5D index: how reliable is the relationship? Health Qual Life Outcomes 2009; 7:27

21 Santini F, Montalbano G, Messina A, et al. Survival and quality of life after repair of acute type A aortic dissection in patients aged 75 years and older justify intervention. Eur J Cardiothorac Surg 2006;29(3):386-391

22 Küchler T, Bestmann B, Rappat S, Henne-Bruns D, WoodDauphinee S. Impact of psychotherapeutic support for patients with gastrointestinal cancer undergoing surgery: 10-year survival results of a randomized trial. J Clin Oncol 2007;25(19): 2702-2708

23 Houle J, Doyon O, Vadeboncoeur N, Turbide G, Diaz A, Poirier P. Effectiveness of a pedometer-based program using a socio-cognitive intervention on physical activity and quality of life in a setting of cardiac rehabilitation. Can J Cardiol 2012;28(1):27-32 